\title{
INCIDENCIA DE LAS NORMAS INTERNACIONALES PARA LA PROTECCIÓN DE LOS TRABAJADORES MIGRANTES IRREGULARES EN COLOMBIA
}

\author{
María Alejandra Salazar Rojas \\ Universidad Católica de Colombia
}

\section{Resumen}

En la globalización, el fenómeno de la migración afecta a todos los países, aunque de diferente forma. Los Estados desarrollan políticas para el acceso legal de los inmigrantes; sin embargo, en muchas ocasiones, existe un alto ingreso de migración irregular. En este contexto, el Derecho Público internacional ha desarrollado una serie de estándares para la protección de los derechos de los inmigrantes irregulares. El presente artículo tiene por objeto analizar dichos estándares en el caso colombiano.

Palabras clave: migración, trabajo, Derecho, sistema social.

La autora: abogada de la Universidad Santiago de Cali, doctoranda en Derecho, de la Universidad Externado de Colombia. Asesora y consultora jurídica en asuntos nacionales e internacionales del Derecho Administrativo, Migratorio y de Extranjería. Correo electrónico: alejandrasrderecho@gmail.com

Recibido: 28 de agosto de 2016; evaluado: 11 de septiembre de 2016; aceptado: 29 de septiembre de 2016. 


\title{
THE IMPACT OF INTERNATIONAL STANDARDS ON THE PROTECTION OF IRREGULAR MIGRANT WORKERS IN COLOMBIA
}

\author{
María Alejandra Salazar Rojas \\ Universidad Católica de Colombia
}

\begin{abstract}
In globalization, the phenomenon of migration affects all countries, albeit in different ways. States develop policies for the legal access of immigrants; however, in many cases, there is a high entry of irregular migration. In this context, Public International Law has developed a series of standards for the protection of the rights of irregular immigrants. The purpose of this article is to analyze these standards in the case of Colombia.
\end{abstract}

Keywords: migration, job, Law, social system.

Author: She is a lawyer at the Universidad Santiago de Cali and a PhD student in Law at the Universidad Externado de Colombia. Adviser and legal counsel in national and international affairs of Administrative, Immigration, and Aliens Law. Email: alejandrasrderecho@gmail.com

Received: August 28, 2016; evaluated: September 11, 2016; accepted: September 29, 2016. 


\section{Introducción}

El fenómeno de la migración irregular, en especial, el de los trabajadores migrantes en condición de irregularidad y sus familias, resulta bastante complejo, porque no se tienen cifras exactas que permitan cuantificar el análisis y también por la difícil conjunción entre la teoría, la producción legislativa y la realidad social.

Estados Unidos es uno de los pocos países del mundo que ha logrado una articulación más pragmática, sin que sea la ideal. Cuenta con estimaciones confiables sobre la población indocumentada, con base en datos gubernamentales recopilados mediante censo. Según recientes estadísticas, se estima que en ese país viven 11,1 millones de migrantes en situación irregular. ${ }^{1}$

Por su parte, en la Unión Europea aún no se han creado ni aplicado mecanismos confiables y sistemáticos de recopilación de datos sobre esta materia. En los últimos años, algunos estudios se han centrado en la medición del número total de migrantes en situación irregular en la Unión Europea. No obstante, estos análisis suelen verse afectados por problemas de incongruencias terminológicas y datos incompletos y no susceptibles de comparaciones entre Estados. Los Estados miembros de la UE tienen diferentes criterios para identificar a esta población y la migración irregular registrada consiste en datos de detenciones en fronteras o entradas irregulares. ${ }^{2}$

Con el texto se busca revisar el fenómeno colombiano de la migración con estándares del Derecho Internacional público y una metodología cualitativa a partir del análisis documental. Se aplica como enfoque teórico el neoconstitucionalismo.

\section{Acercamiento al caso colombiano}

En el caso colombiano, la cifra de extranjeros en situación irregular no puede ser determinada, ya que Migración Colombia solo cuenta con los registros de los extranjeros regulares que ingresan al país con un permiso de ingreso y permanencia (PIP), un permiso temporal de permanencia (PTP) o una visa en cualquiera de sus categorías. ${ }^{3}$

1 Pablo Ceriani Cernadas, Michele LeVoy y Lilana Keith, "Indicadores de derechos humanos para migrantes y sus familias" http://www.knomad.org/docs/migrant_rights/KNOMAD\%20Documento\%20de\%20Trabajo\%20 5\%20Indicadores\%20de\%20derechos\%20humanos\%20para\%20migrantes.pdf (acceso mayo 23, 2016), 48. Ceriani Cernadas, LeVoy y Keith, "Indicadores de derechos humanos", 49-50.

En relación con los trabajadores migrantes en situación regular, el Ministerio del Trabajo manifestó que: "Desde el segundo semestre del año 2014, la Cancillería y Migración Colombia vienen trabajando de la mano con el 
Así, acerca de los extranjeros que ingresan irregularmente al país, no hay registros que permitan señalar cuántos son con exactitud, puesto que la misma dinámica migratoria, sobre todo en las zonas de fronteras con movilidad asociada con temas laborales y sociales, imposibilita medir los flujos migratorios de una población que, en la mayoría de los casos, es flotante. Solo cuando se adelantan actividades de verificación migratoria y se determina que un extranjero ha ingresado irregularmente al país se inicia un proceso administrativo para definir su situación, que por lo general deriva en la imposición de una medida sancionatoria. ${ }^{4}$

Esta situación evidencia que la clasificación como irregular de los trabajadores migrantes en Colombia se puede configurar de dos maneras: por ingreso irregular o por adquirir la condición migratoria irregular con posterioridad a su ingreso regular. De acuerdo con las normas internacionales aplicables en Colombia (C. 97, art. 6; R. 86, párr. 16, 1); C. 143, arts. 10 y 12, b) y g); R. 151, párr. 2), el Estado colombiano tiene el deber de garantizar que los trabajadores migrantes y sus familiares en situación irregular en el país disfruten de unas oportunidades y un trato equivalente al que se dispensa a los nacionales en materia de empleo y ocupación; condiciones de trabajo; derechos sindicales; alojamiento (vivienda); seguridad social y procedimientos legales.

Todo lo anterior refiere que las normas internacionales inciden de manera benévola en la situación de inmigración irregular, en especial en Estados como Colombia, en donde no se han ratificado las normas internacionales de trabajo y de la Resolución ONU 45/158 de 1990, que son las únicas herramientas garantistas de los derechos fundamentales por la sola condición de ser persona y no por un estatus migratorio.

Departamento Administrativo Nacional de Estadística, en la implementación de mecanismos de generación de estadísticas de calidad. En el primer semestre 2014, ingresaron 41.701 extranjeros a Colombia según la categoría Temporal Trabajador. Los flujos de ingreso de trabajadores temporales extranjeros, por nacionalidad, se constituyeron principalmente por venezolanos, $15 \%$, estadounidenses, $10 \%$, españoles $7 \%$, ecuatorianos $7 \%$ y mexicanos 5\%. Durante el trimestre mayo-julio de 2014, 30.443 extranjeros cotizaron en el Sistema de Seguridad Social. El 61,3\% cotizó como dependiente (18.665), 27,2\% como independiente (8.294), 3,1\% como independiente agremiado (940), 2,6\% como profesor de establecimiento particular (790), y el 5,8\% cotizó bajo otras modalidades". Ministerio de Trabajo, Respuesta a derecho de petición de 23 de abril de 2015.

4 Ministerio de Trabajo, Respuesta a derecho de petición de 23 de abril de 2015. 


\section{Escuelas del pensamiento jurídico}

El neoconstitucionalismo es un modelo teórico que transforma los paradigmas del Derecho frente a principios como el de legalidad, legitimidad y validez, con el fin de modificar la producción legislativa.

También cambia los criterios jurisdiccionales, pues considera que el juez tiene el deber de reprochar como inválida una norma por medio del control de constitucionalidad. Este criterio académico subordina la regla al respeto de los principios constitucionales que, para Alexy y Ferrajoli, se traduciría al modelo de pensamiento jurídico que limita el poder con el propósito de garantizar los derechos fundamentales.

Hay seis razones del contenido de esta escuela:

Primero, carácter normativo o fuerza vinculante. La Constitución no es un catecismo o guía moral, sino una norma como cualquier otra que incorpora la pretensión de que la realidad se ajusta a lo que ella prescribe.

Segundo, la supremacía o superioridad jerárquica en el sistema de fuentes. La Constitución no sólo es una norma sino que es la norma suprema, y ello significa que condiciona la validez de todos los demás componentes del orden jurídico y que representa frente a ellos un criterio de interpretación prioritario.

Tercero, eficacia o aplicación directa. No requiere de ningún otro acto jurídico -ley_ para desplegar su fuerza vinculante.

Cuarto, garantía judicial. Las posibilidades son amplias: control concreto y abstracto, a priori y a posteriori, encomendado a órganos especiales o a jueces ordinarios.

Quinto, presencia de un denso contenido normativo, formado por principios, derechos y directrices.

Y sexto y último lugar, la rigidez constitucional (cursivas propias). ${ }^{5}$

5 Raymundo Gil Rendón, "Neoconstitucionalismo y los derechos fundamentales", Quid Iuris 12 (2011): 52. 
Por demás estas seis razones del contenido del nuevo constitucionalismo se sustentan a su vez desde los planteamientos de los derechos fundamentales de Alexy y Ferrajoli. ${ }^{6}$

\author{
Para, Alexy, los derechos fundamentales ${ }^{7}$ son: i) normas expresas en la Constitu- \\ ción, es decir, están plasmadas en el texto constitucional, o ii) adscritas que tienen \\ una argumentación iusfundamental en su contenido. En sus propias palabras, "los \\ derechos fundamentales son todos los derechos catalogados expresamente como \\ tales por la propia Constitución". ${ }^{8}$ En ese contexto teórico, los problemas que se \\ causen entre principios requieren el ejercicio de la ponderación. ${ }^{9}$
}

6 Rodolfo Luis Vigo, "Constitucionalización y neoconstitucionalismo: algunos riesgos y algunas prevenciones", Revista de la Facultad de Ciencias Jurídicas y Sociales, núm. 7 (2009): 257.

7 Al respecto Alexy también consideró que "los derechos fundamentales son esencialmente derechos del individuo". Robert Alexy, Tres escritos sobre los derechos fundamentales y la teoría de los principios (Bogotá: Universidad Externado de Colombia, 2003), 25.

8 Alexy, Tres escritos sobre los derechos fundamentales y la teoría de los principios, 21.

$9 \quad$ "Tal como se ha expuesto, el procedimiento de ponderación es un procedimiento racional pero, no es un procedimiento que en cada caso conduzca a exactamente una única solución. Cuál sea la solución que, después de una ponderación se considere correcta, depende de valoraciones que no son ellas mismas controlables por medio del propio procedimiento de la ponderación". Robert Alexy, Teoría de los derechos fundamentales (Madrid: Centro de Estudios Constitucionales, 1993), 482.

Explica Bernal Pulido: "[...] es pertinente reconocer que la aplicación del principio de proporcionalidad y de la ponderación no puede ser plenamente racional, en el sentido de que constituya un algoritmo para la aplicación de los derechos fundamentales. Los críticos llevan razón cuando afirman que la ponderación tiene un carácter formal y que, por tanto, no puede excluir las apreciaciones subjetivas del juez. La ponderación no puede garantizar este tipo de objetividad plena, porque semejante objetividad es una utopía que no puede alcanzarse en ningún ámbito normativo". Carlos Bernal Pulido, "Estudio introductorio a la teoría de los derechos fundamentales de Robert Alexy" en Teoría de los derechos fundamentales, Robert Alexy (Madrid: Centro de Estudios Constitucionales, 1993), XLV.

También debe señalarse que "Se trata, en suma, de que el derecho sea algo que los ciudadanos pueden entender y no algo a lo que ciertos sacerdotes del derecho, imbuidos de no se sabe qué extraño don, tienen acceso exclusivo en virtud de su innata sintonía con la esencia de los conceptos o la verdad de los valores materiales". Juan Antonio García Amado, "La interpretación constitucional", Revista Jurídica de Castilla y León, núm. 2 (2004): 43. Destaca lo abstracta que resulta la diferencia propuesta entre una regla y un principio: "La explicación de Alexy sobre qué es una regla o un principio no dice nada: 'Si se pondera es un principio, si se subsume es una regla' y cómo se sabe si se pondera o se subsume y la respuesta es 'porque si es un principio hay que ponderarlo y si es una regla hay que subsumirlo', 'principios derrotan a principios, y principios derrotan a reglas y cuando choca una regla con otra regla, entonces en realidad es un choque de principios porque a toda regla le subyace un principio'. En esa medida una norma puede ser una regla, un principio o una regla de validez estricta, de qué depende, pues de lo que quiera el aplicador". Juan Antonio García Amado, ¿Dónde va el Derecho actual? (Santiago: Universidad Alberto Hurtado, 2010). En sentido similar, Paolo Comanducci sostiene: "[El neoconstitucionalismo] implica la atribución a los jueces constitucionales de un margen tan amplio de discrecionalidad que los convierte no sólo en colegisladores sino incluso, en algunos casos, en coautores de la misma constitución. También provoca esa opción que los márgenes de certeza del derecho de que goza el ciudadano se estrechen considerablemente". Paolo Comanducci, Constitución y teoría del Derecho (Ciudad de México: Fontamara, 2007), 71. 
Por su parte, Ferrajoli considera que los derechos fundamentales son aquellas normas "inalienables, indisponibles, inviolables, intransigibles y personalísimas"10 de toda persona y que "los derechos fundamentales son siempre leyes del más débil contra la ley del más fuerte". "Señala que las realidades sociales fueron transformadas a partir de la Carta de Naciones Unidas de 1945 y la Declaración universal de los derechos del hombre, de 1948, debido al plano normativo donde los Estados quedaron obligados al respeto y aplicabilidad ontológica de tales normas, más allá de su soberanía. ${ }^{12}$

A causa de lo anterior, Ferrajoli ${ }^{13}$ señala que nos enfrentamos al cambio de la estructura de los derechos en relación con la realidad social mundial, a partir de la soberanía y la ciudadanía (exclusión, inclusión y el Rechtsstaat) ${ }^{14}$ y de los derechos humanos y el constitucionalismo, por lo cual insiste en la reflexión de tres cuestiones principales a la teoría jurídica:

a) la ausencia de garantías judiciales a nivel internacional;

b) el cambio de lugar de las respectivas garantías constitucionales como consecuencia de la debilitación de la soberanía estatal;

c) la posibilidad de un derecho de asilo como contrapeso; si bien débil de la concepción estatista de los derechos humanos derivada de la ciudadanía. ${ }^{15}$

10 Rafael Enrique Aguilera Portales y Rogelio López Sánchez, Los derechos fundamentales en la teoría jurídica garantista de Luigi Ferrajoli (Ciudad de México: Instituto de Investigaciones Jurídicas de la UNAM, 2004), 57-60.

11 Luigi Ferrajoli, "Sobre los derechos fundamentales", Cuestiones constitucionales, núm. 15 (2006): 131.

12 Para Ferrajoli, las normas aludidas obedecen a la estructura que él concibió como garantismo. Afirmó: "Mi tesis, además, indica que este garantismo puede ser y ha sido históricamente desarrollado por el constitucionalismo, no solo frente a los derechos de libertad, sino también a los sociales, como sistema de límites y prohibiciones a cargo de la esfera pública, y de vínculos, como los derechos a la salud, a la vida, a la dignidad, al trabajo, etc., que requieren garantías diversas del derecho a la libertad. Esto también ocurre cuando se crean prohibiciones a la policía, a la administración, al poder político, al Ejecutivo, a la judicatura, etc., que consisten en obligaciones de prestaciones. La doctrina dominante no toma en serio los derechos sociales, pues los considera opcionales, a partir de decisiones políticas". Ámbito Jurídico, "Luigi Ferrajoli: "La pacificación es un presupuesto de la construcción de un Estado de Derecho" [Entrevista con Luigi Ferrajoli], ambitojuridico. com, 28 de noviembre, 2013, https://www.ambitojuridico.com/BancoConocimiento/Educacion-y-Cultura/ noti-131128-01-luigi-ferrajoli-la-pacificacion-es-un-presupuesto-de-la-construccion-de-un-estado.cshtml (acceso noviembre 30, 2013).

13 Luigi Ferrajoli, "Más allá de la soberanía y la ciudadanía: un constitucionalismo global", Revista de Teoría y Filosofía del Derecho, núm. 9 (1998): 32

14 Término alemán concebido como Estado de Derecho.

15 Victor Abramovich y Chistian Coustis, Los derechos sociales como derechos exigibles (Madrid: Trotta, 2002 ), 7. 


\section{Aspectos conceptuales}

El manejo lingüístico dado a los vocablos que circundan la temática propia de las migraciones hace perenne la precisión de algunos términos que serán usados en este artículo, por lo cual se presentan algunos de manera muy general:

\section{Cuadro 1. Los usos conceptuales}

\begin{tabular}{|l|l|l|}
\hline \multicolumn{1}{|c|}{ Término } & \multicolumn{1}{|c|}{ Entidad } & \multicolumn{1}{c|}{ Concepto } \\
\hline Migrante & Propio & Sujeto que viaja a un Estado diferente al de su nacionalidad. \\
\hline Inmigrante & Propio & $\begin{array}{l}\text { Sujeto que ingresa a un Estado con el ánimo de permanecer } \\
\text { en él. }\end{array}$ \\
\hline Emigrante & Propio & $\begin{array}{l}\text { Sujeto que viaja desde su Estado o Nación a otro con el } \\
\text { ánimo de residir en el país de acogida. }\end{array}$ \\
\hline Trabajador no autorizado & $\begin{array}{l}\text { Comisión Interamericana } \\
\text { de Derechos Humanos }\end{array}$ & $\begin{array}{l}\text { Trabajadores migrantes que no poseen autorización para ser } \\
\text { contratados legalmente. Este grupo incluye a trabajadores } \\
\text { que, por diversas razones, se encuentran legalmente, pero } \\
\text { no tienen autorización para trabajar. }\end{array}$ \\
\hline Migrante indocumentado & $\begin{array}{l}\text { Comisión Interamericana } \\
\text { de Derechos Humanos }\end{array}$ & $\begin{array}{l}\text { Migrantes cuya presencia en un Estado es ilegal. Estos traba- } \\
\text { jadores forman un subgrupo de la población migrante que no } \\
\text { está autorizada a trabajar. La mayoría de las decisiones de } \\
\text { los tribunales están basadas en la autorización para trabajar. }\end{array}$ \\
\hline
\end{tabular}

Fuente: elaboración propia

\section{Normas internacionales y nacionales para la protección de los trabajadores migrantes irregulares: análisis desde la realidad colombiana}

Estos aportes teóricos sirven para señalar que los migrantes en Colombia están cobijados por el Sistema universal de derechos humanos en el contexto de las Naciones Unidas y las normas internacionales de trabajo y, en el escenario regional, por el Sistema Interamericano de Derechos Humanos. En este último, los problemas en derechos humanos son aún más graves en el caso de la migración irregular, pues los trabajadores no documentados o en situación irregular con frecuencia son empleados en condiciones de trabajo menos favorables.

Aquí inicia una disyuntiva interesante y es que a raíz de la aprobación de la Ley 146 de 1994 "Por medio de la cual se aprueba la 'Convención internacional sobre la protección de los derechos de todos los trabajadores migratorios y de sus familiares', 
hecha en Nueva York el 18 de diciembre de 1990", ${ }^{16}$ se crea el único instrumento internacional de derechos humanos que hace referencia explícita a los derechos de los migrantes. De entrada, requiere una modificación sustentada en la teoría neoconstitucional para comprender la realidad social de los inmigrantes que se encuentran en situación administrativa irregular en nuestro país.

Por ejemplo, según el Comunicado de prensa No. 40 de Migración Colombia, entre junio y julio de 2016 se deportaron más de 5.800 migrantes que se encontraban en situación irregular en el país de los cuales la entidad no tenía registros antes de su deportación.

Aun cuando se puede establecer una relación entre las medidas adoptadas en el país para la protección de los trabajadores migrantes en situación irregular y las disposiciones del Convenio 143 y la Recomendación 151, es claro que el reconocimiento de la protección de este grupo ha sido invisibilizado por el Derecho Internacional e incluso por el nacional. Ello es así porque la gestión de las migraciones resulta compleja y la garantía de ciertos derechos de contenido económico, social y cultural se dificultan al margen del reconocimiento de la legalidad en un Estado.

Si bien es cierto que el debate de la protección de los migrantes en el contexto de los derechos humanos puede apuntar hacia el reconocimiento, el respeto y la garantía de derechos mínimos, inalienables e irrenunciables de las personas naturales en razón a su condición, también es cierto que en Colombia no se evidencia un avance significativo respecto a trabajadores migrantes en situación de irregularidad.

Tal realidad se pudo visualizar con las deportaciones masivas de los casi 950 cubanos que estaban en situación de irregularidad en Colombia, lo que condujo a una violación del Derecho Internacional, en particular a las normas previstas en el año 2004 por la Comisión de Derecho Internacional (CDI) de Naciones Unidas sobre

16 "El Convenio aprobado mediante esta Ley fue promulgado por el Decreto 2084 de 1995. Ley declarada exequible por la Corte Constitucional, mediante Sentencia C-106-95 del 15 de marzo de 1995, pero la exequibilidad de los artículos 15, 46 y 47 se declara bajo el entendido de que el Estado colombiano mantiene su derecho de dictar normas tributarias cambiarias y monetarias que establezcan un trato igual entre trabajadores migratorios y sus familias y los nacionales para la importación y exportación de bienes de uso personal, enseres domésticos, transferencias de ingresos y ahorros hacia el exterior, así como para proceder a la expropiación por razones de equidad y a la extinción del dominio en los eventos previstos en el artículo 34 de la Constitución Política". Congreso de la República de Colombia, Ley 146 de 1994, "Por medio de la cual se aprueba la 'Convención internacional sobre la protección de los derechos de todos los trabajadores migratorios y de sus familiares', hecha en Nueva York el 18 de diciembre de 1990" (Bogotá: Diario Oficial No. 41.444, 15 de julio de 1994). 
las reglas internacionales que rigen la expulsión de extranjeros y su prohibición por la Convención Interamericana de Derechos Humanos.

Esa norma señala que el Estado que expulsa debe ser especialmente cuidadoso con las personas en situación de vulnerabilidad, como los niños o los adultos mayores. Sobre estos aspectos no se pronunció Migración Colombia en sus comunicados acerca de lo que llamó "deportación voluntaria". Tal denominación solo es una cortina proteccionista del ente administrativo, puesto que la deportación colectiva de extranjeros está prohibida en el ámbito internacional.

Además de la Convención Americana de Derechos Humanos, está el Protocolo europeo para la protección de los derechos humanos y las libertades fundamentales, la Carta africana sobre derechos humanos y de los pueblos y la Convención internacional para la protección de trabajadores migrantes, como mecanismos que prohíben este tipo de expulsiones.

Para la Corte Interamericana, cuando las expulsiones no están acompañadas de un análisis objetivo de las circunstancias particulares de cada extranjero, resultan arbitrarias. Según este Tribunal, se requiere que la deportación sea consecuencia de un procedimiento individual que debe estar acompañado de todas las garantías judiciales. ${ }^{17}$

En el caso de los cubanos, se podría sostener que en la mayoría de los casos se omitió la protección al debido proceso: en unos no se efectuó la notificación consular al país de los nacionales, ${ }^{18}$ en otros no se escuchó a los niños y se permitió la continuidad de una ruta de la que se conocen los peligros que pueden correr.

En consecuencia, se observa un carácter improvisado de la respuesta institucional a un fenómeno que ha podido preverse y quizás retornará. Urge una política seria que ofrezca respuestas a los millones de inmigrantes que estarán o que ya residen de manera irregular en nuestro país, que debe atender de manera oportuna cuando sus derechos se vean afectados.

17 Corte Interamericana de Derechos Humanos, Caso Nadege Dorzema y otros vs. República Dominicana, Sentencia de 24 de octubre de 2012, párr. 171; Caso del Tribunal Constitucional vs. Perú, Sentencia de 31 de enero de 2001 (fondo, reparaciones y costas), párr. 71 y ss.; Caso Barbani Duarte y otros vs. Uruguay, Sentencia de 13 de octubre de 2011 (fondo, reparaciones y costas), Serie C No. 234, párrs. 118 y 119; Opinión consultiva condición jurídica y derechos de los migrantes indocumentados de 17 de septiembre de 2003, párr. 117; Caso Vélez Loor vs. Panamá. Sentencia de 23 de noviembre de 2010.

18 Corte Interamericana de Derechos Humanos, Opinión consultiva OC-16/99 del 1 de octubre de 1999. 


\section{Conclusiones}

Medidas para regular a los trabajadores migrantes en situación irregular

- $\quad$ En el neoconstitucionalismo axiológico, los actores políticos y sociales toman el ejercicio discursivo de la Constitución. Así pues, las Constituciones fomentan la autonomía personal, la inclusión, la igualdad y condiciones de deliberación. ${ }^{19}$

- El neoconstitucionalismo está ligado al Estado constitucional, sustentado en las columnas de la libertad, del límite a los poderes y de la búsqueda de la validez normativa, la justicia, la idoneidad y la pertinencia normativa.

- El neoconstitucionalismo es un paradigma constitucional que rige según la época y plantea el respeto por las garantías fundamentales bajo los límites al poder, en el que los ciudadanos deben hacerse responsables de que los mismos sean protegidos.

- $\quad$ El neoconstitucionalismo integra un modelo moral, de valores, que migró al Derecho y propende porque el ordenamiento constitucional esté garantizado en sede judicial.

- El neoconstitucionalismo es un desarrollo teórico novedoso en el que los principios son vistos como mandatos de optimización. ${ }^{20}$

- Los Estados modernos solo se legitiman con la realización de los derechos fundamentales. El neoconstitucionalismo implica una reforma a la cultura jurídica y los temas de seguridad estatal comprenden una escala imaginaria que siempre estará por debajo de tales garantías.

- Trasplantar teorías extranjeras sin el estudio de las realidades sociales solo invisibiliza los retos a los cuales está supuesto el Estado.

- La teoría del neoconstitucionalismo se presenta como el aporte del pensamiento jurídico más cercano a los retos que afrontan los inmigrantes colombianos en el día a día.

- Los problemas migratorios se deben entender a partir de las culturas y de reconocimiento a los demás por la sola condición de ser persona.

19 Roberto Gargarella, La justicia frente al Gobierno (Barcelona: Ariel, 1996).

20 Alexy, Teoría de los derechos fundamentales 117. 
- Lo anterior significa que es necesario: i) comprender la realidad social de los migrantes, y ii) proponer mecanismos para disminuir la trasgresión a los derechos inherentes, así como incentivar la creación de teorías que fomenten la interpretación de las problemáticas y los retos que engloba la migración.

\section{Recomendaciones al Estado colombiano}

- Crear una dependencia de la Rama Ejecutiva que permita el acompañamiento de expertos en la materia para proponer y servir de guía en los proyectos de reforma y creación normativa. Esta dependencia requeriría el acompañamiento de expertos interdisciplinarios y con un enfoque moral e intercultural.

- Crear un Tribunal nacional para asuntos de extranjería y migratorios de carácter jurisdiccional.

- Pensar en una garantía de viaje que esté soportada por un ente estatal. Esta póliza podría prevenir aspectos de seguridad nacional y ser un motor de oportunidades para la prevención de la inmigración irregular y, con ello, abrir las fronteras.

\section{Referencias}

Abramovich, Victor y Chistian Coustis. Los derechos sociales como derechos exigibles. Madrid: Trotta, 2002.

Aguilera Portales, Rafael Enrique y Rogelio López Sánchez. Los derechos fundamentales en la teoría jurídica garantista de Luigi Ferrajoli. Ciudad de México: Instituto de Investigaciones Jurídicas de la UNAM, 2004.

Alexy, Robert. Teoría de los derechos fundamentales. Madrid: Centro de Estudios Constitucionales, 1993.

Alexy, Robert. Tres escritos sobre los derechos fundamentales y la teoría de los principios. Bogotá: Universidad Externado de Colombia, 2003.

Ámbito Jurídico. "Luigi Ferrajoli: 'La pacificación es un presupuesto de la construcción de un Estado de Derecho" [Entrevista con Luigi Ferrajoli]. ambitojuridico.com, 28 de noviembre, 2013. https://www.ambitojuridico.com/BancoConocimiento/Educaciony-Cultura/noti-131128-01-luigi-ferrajoli-la-pacificacion-es-un-presupuesto-de-laconstruccion-de-un-estado.cshtml (acceso noviembre 30, 2013).

Bernal Pulido, Carlos. "Estudio introductorio a la teoría de los derechos fundamentales de Robert Alexy" en Teoría de los derechos fundamentales, (traducción de Carlos Bernal 
Pulido), Robert Alexy, XXIII - LV. Madrid: Centro de Estudios Políticos y Constitucionales, Madrid, segunda edición en castellano, 2008.

Ceriani Cernadas, Pablo, Michele LeVoy y Lilana Keith. "Indicadores de derechos humanos para migrantes y sus familias". http://www.knomad.org/docs/migrant_rights/ KNOMAD\%20Documento\%20de\%20Trabajo\%205\%20Indicadores\%20de\%20 derechos\%20humanos\%20para\%20migrantes.pdf (acceso mayo 23, 2016).

Comanducci, Paolo. Constitución y teoría del Derecho. Ciudad de México: Fontamara, 2007. Congreso de la República de Colombia. Ley 146 de 1994, "Por medio de la cual se aprueba la 'Convención internacional sobre la protección de los derechos de todos los trabajadores migratorios y de sus familiares', hecha en Nueva York el 18 de diciembre de 1990". Bogotá: Diario Oficial No. 41.444, 15 de julio de 1994.

Corte Interamericana de Derechos Humanos. Caso Barbani Duarte y otros vs. Uruguay. Sentencia de 13 de octubre de 2011 (fondo, reparaciones y costas).

Corte Interamericana de Derechos Humanos. Caso del Tribunal Constitucional vs. Perú. Sentencia de 31 de enero de 2001 (fondo, reparaciones y costas).

Corte Interamericana de Derechos Humanos. Caso Nadege Dorzema y otros vs. República Dominicana. Sentencia de 24 de octubre de 2012.

Corte Interamericana de Derechos Humanos. Caso Vélez Loor vs. Panamá. Sentencia de 23 de noviembre de 2010.

Corte Interamericana de Derechos Humanos. Opinión consultiva OC-16/99 del 1 de octubre de 1999.

Corte Interamericana de Derechos Humanos. Opinión consultiva condición jurídica y derechos de los migrantes indocumentados de 17 de septiembre de 2003.

Ferrajoli, Luigi. "Más allá de la soberanía y la ciudadanía: un constitucionalismo global". Revista de Teoría y Filosofía del Derecho, núm. 9 (1998): 177-181.

Ferrajoli, Luigi. "Sobre los derechos fundamentales". Cuestiones constitucionales, núm. 15 (2006): 113-136.

García Amado, Juan Antonio. ¿Dónde va el Derecho actual? Santiago: Universidad Alberto Hurtado, 2010.

García Amado, Juan Antonio. "La interpretación constitucional”. Revista Jurídica de Castilla y León, núm. 2 (2004): 37-74.

Gargarella, Roberto. La justicia frente al Gobierno. Barcelona: Ariel, 1996.

Gil Rendón, Raymundo. "Neoconstitucionalismo y los derechos fundamentales". Quid Iuris 12 (2011): 43-61.

Ministerio de Trabajo. Respuesta a derecho de petición de 23 de abril de 2015.

Vigo, Rodolfo Luis. "Constitucionalización y neoconstitucionalismo: algunos riesgos y algunas prevenciones". Revista de la Facultad de Ciencias Jurídicas y Sociales, núm. 7 (2009): 255-288. 